\title{
Nurse educators' reflections on factors that contributed to their resignation at a public nursing college in Johannesburg, South Africa
}

\author{
Vhothusa Edward Matahela* \\ Nursing Education and Training Directorate, National Department of Health, South Africa
}

Received: May 28, 2021

DOI: $10.5430 /$ jnep.v11n12p61

\author{
Accepted: August 2, 2021 \\ Online Published: August 18, 2021 \\ URL: https://doi.org/10.5430/jnep.v11n12p61
}

\begin{abstract}
Background and objective: There is a shortage of nurses in the country and worldwide, and the problem is compounded by the resignation of nurse educators. When nurse educators resign, they leave with their expertise and skills, thus compromising the provision of quality teaching and learning in the institution. It is imperative that a study to determine the factors contributing to the resignation of nurse educators be conducted. The aim of the study was to explore and describe the factors that contributed to the resignation of nurse educators at a Johannesburg nursing college in South Africa.

Methods: A qualitative, exploratory, descriptive and contextual research design was used to provide an in-depth description of factors that contributed to nurse educators resigning from a Johannesburg nursing college. Individual semi-structured interviews were conducted with 15 purposively selected nurse educators, using audiotapes until data saturation. Data were analysed by the researcher and an independent coder using the Tesch protocols on thematic analysis. Trustworthiness was achieved using Lincoln and Guba's strategies.

Results: Three themes emerged, namely: experience of an unappreciative working environment; negative influences on the 'self' of the nurse educator; and the need for career advancement and professional growth.

Conclusions: The provision of quality nursing education to produce nurses will be difficult in the face of nurse educators resigning from their posts. There is a need to implement retention strategies to create an appreciative working context for nurse educators in the institution.
\end{abstract}

Key Words: Nurse educators, Nursing college, Retention, Resignation, Reflection, South Africa

\section{INTRODUCTION}

The nursing profession is facing a staff shortage crisis worldwide, and South Africa is no exception. ${ }^{[1]}$ This crisis is due to a shortage of all categories of nurses in general, and nurse educators in particular. ${ }^{[2]}$ The shortage threatens the sustainability of health care systems and negatively affects the achievement of sustainable development goals as well as the implementation of universal healthcare. ${ }^{[3]}$ In addition, shortage of nurse educators has negative effects on the country's healthcare system, as the nursing profession's ability to provide leadership and research in addressing health care issues will be diminished. ${ }^{[4]}$

The South African national Department of Health (NDoH) recognises that the resignation of nurse educators contributes to nursing staff shortages and that this is one of the constraints in attaining its goals. Such is the importance of nurse

\footnotetext{
*Correspondence: Vhothusa Edward Matahela; Email: vhothusa@yahoo.com; Address: Nursing Education and Training Directorate, National Department of Health, South Africa. 
educator retention that the NDoH has in consecutive published nursing strategies in 2008, 2013 and 2020, highlighted the need for comprehensive retention of nurse educators to ensure provision, promotion, and maintenance of a high standard of nursing education. ${ }^{[4-6]}$

Nursing organisations in the country, such as the Democratic Nursing Organisation of South Africa (DENOSA), also realise the need to retain nurse educators. DENOSA identified the lack of staff retention strategies, including those specific to nurse educators, as one of the challenges leading to a shortage of nurses in health services. ${ }^{[7]}$ There has been a suggestion ${ }^{[7]}$ that the Occupation-Specific Dispensation (OSD), which is a 2007 government strategy to revise salary structures of identified public occupations including nursing, be reviewed to consider nurses' years of service in government and additional qualifications that nurses may have acquired over the years. Whilst evidence suggests that remuneration and financial rewards influence retention of staff, Willis-Shattuck and colleagues ${ }^{[8]}$ caution against sole use of financial incentives as a retention strategy.

Employees leave their jobs for various reasons, and it is therefore important for the employer to ascertain, record, and track the various reasons why employees leave an institution. ${ }^{[9]}$ Some nurse educators resign to join the private sector, and those with more years of experience tend to be dissatisfied with promotion opportunities. Experienced nurses are difficult to retain within the nursing discipline as they are skilled, have a wealth of experience and dedication, and as such they are highly sought after. ${ }^{[10,11]}$ Some authors ${ }^{[12,13]}$ have observed that nurse educators often take unfinished college work home, and this can be quite stressful.

Factors such as burnout, lack of autonomy, absence of proper incentives, insufficient support, workload, emotional exhaustion, and continuous pressure can lead to educators resigning. ${ }^{[14]}$ Although a nurse educator's primary role is teaching students, they are also required to participate in a myriad of other activities and projects such as college committees, community outreach programmes, research, and scholarly presentations. Fulfilling the demands of all these activities can lead to stress. ${ }^{[13]}$

The challenge with nurse educator retention is further exacerbated by ageing nurse educators who reach retirement age and leave teaching. These are nurse educators with intellectual capital, wisdom, leadership expertise, and a wealth of skills and abilities to offer the workforce. ${ }^{[15]}$ Such nurse educators would also be valuable in the mentoring of younger, less-experienced nurse educators as they transition from the nursing role to the nurse educator role. ${ }^{[10,16]}$ Some South African nurse educators resign from nursing colleges and take their expertise and experience overseas where they receive better remuneration. ${ }^{[7,17]}$ There is growing concern that that the migration of experienced nurse educators will lead to a situation in which there will be insufficient educators to train an adequate health workforce in developing countries such as South Africa. ${ }^{[3,18]}$

Qualified nurses from South Africa are highly sought for their skills and they emigrate to developed countries, resulting in a brain drain. Although South Africa is the richest country in the Southern Africa Development Community (SADC) region and has the second highest gross domestic product in Africa, it has experienced a net outflow of academic professionals to countries such as the UK, Canada and Australia. ${ }^{[18]}$ While nurse educator salaries slightly improved after implementation of the OSD, remuneration levels are potentially the most influential factor in nurse educators' decision to migrate, either between the public and private sector, or to richer countries. ${ }^{[18]}$

The nursing college understudy is situated in the city of Johannesburg in the Gauteng Province. With a population of 4.4 million residents, the city is the largest single metropolitan contributor to the national economic product. The city is one of the world's leading financial centres and it is the economic and financial hub of South Africa, producing 16\% of the country's gross domestic product, and accounts for $40 \%$ of Gauteng's economic activity. ${ }^{[19]}$ Despite its relative economic fortunes, the city is marred by high poverty rates, inequalities in the distribution of income between various population subgroups, and the highest unemployment rate compared to other cities in the country. It is for this reason that the provincial government identified nursing as one of the employment opportunities for the unemployed to enter the job market. ${ }^{[20]}$ During the years under study, students used to receive salaries whilst in training. Thus, large numbers of students could easily be recruited into nurse training as they were motivated by the fact that they could receive salaries whilst studying. ${ }^{[20]}$

Compounding the problem of the shortage of nurse educators at the college under study, was the non-negotiable mandate by provincial health authorities to increase the intake of first-year students by $25 \%$ annually from 2009 onwards for all public nursing colleges located in the Gauteng Province. During that period, the number of new students in Gauteng Province rose from 828 in 2004 to 1520 in 2008. ${ }^{\text {[21] } \mathrm{By}}$ 2016, there were 3185 students enrolled in Gauteng nursing colleges. ${ }^{[22]}$ These students are enrolled in the four-year Diploma in Nursing (General, Community \& Psychiatry) and Midwifery. The implication of this increase in student numbers, compounded by nurse educator resignations, is that 
there would be a greater workload for those nurse educators who remained teaching at the nursing colleges. Fundamentally, the increase in student numbers was not matched by human and infrastructural resources.

The researcher was concerned that as the number of students increased each year, there were nurse educators who resigned from teaching in Gauteng provincial nursing colleges. The continuous resignations of nurse educators made it challenging for the nursing colleges to provide quality education to students, due to factors such as large classes and overcrowded clinical environments. ${ }^{[2]}$ This was in contrast to the standards set by the South African Nursing Council, ${ }^{[23,24]}$ that requires a nurse educator-student ratio of $1: 15$ in clinical training platforms, and 1:30 in the classroom at a given time. This ratio could not be maintained if nurse educators continued to resign and the student intake continued to increase, and this would affect the government's health vision of reducing the shortage of nurses and providing optimal health care for all. ${ }^{[25]}$

The $\mathrm{WHO}^{[18]}$ advice to employers is to improve their employee retention strategies by focusing on factors that they can control internally. It is therefore imperative that colleges develop retention strategies to meet the growing demand of producing more nurses. It was crucial that a study to determine the factors that contributed to the resignation of nurse educators be conducted to provide more information for college managers and policymakers, who could then focus on more effective retention strategies to manage the human resources in nursing colleges.

The following questions guided the study, and were asked of the participants during the interviews:

- What are the factors that contributed to your resignation from a Johannesburg nursing college; and

- What can be done to retain nurse educators at a Johannesburg nursing college?

\section{Methodology}

\subsection{Design}

A contextual qualitative, exploratory and descriptive research design was used to conduct individual semi-structured interviews. Qualitative research provided an opportunity for the exploration and in-depth description of factors that contributed to the resignation of nurse educators from a Johannesburg nursing college.

\subsection{Population and sampling}

College records showed that more than 100 nurse educators had resigned between the years 2000-2010. The sample in this study consisted of 15 participants who responded to invitations to be part of the study. The participants were purposively selected because they had in-depth information regarding factors that contributed to the resignation of nurse educators at a Johannesburg nursing college.

\subsection{Data collection}

A pilot study was conducted with one participant, who had resigned but was not involved in the actual research, and this assisted in determining the feasibility of the selected research methods, procedures and research question. Data collected in the pilot interview were included in the main study, as the interview was a success. Individual face-to-face, semi-structured interviews were used to gather information from the nurse educators who had resigned from the subject college. The participants were interviewed in English between September 2012 and January 2013, in settings of their choice, where they felt more comfortable. Some were interviewed at their homes, whilst others were interviewed at local schools, as well as in churches.

Each individual interview lasted 45 to 60 minutes, depending on data saturation. Open-ended research questions were asked by an independent interviewer who was purposively selected because of her knowledge of qualitative research and her interviewing skills. ${ }^{[26]}$ The responses from the nurse educators were recorded on an audiotape recorder with the permission of the participants. The researcher assisted with the management of the tape recorder and took field notes during the interviews to increase the credibility of the information collected. Field notes were of value because they were used to enrich the audiotape recordings and assisted the researcher with the verbatim transcription of the data. Communication dynamics were noted during the interviews, especially the non-verbal cues. The tape-recorded interviews were transcribed verbatim after interviews.

\subsection{Data analysis}

Each interview was transcribed verbatim as soon as the interview had been conducted. This enabled the researcher to become familiar with the data as he listened to the tapes, re-read the transcripts and field notes, and thus became immersed in the data. An open coding, qualitative data analysis method was conducted manually by the researcher in accordance with the Tesch protocols. ${ }^{[27]}$ This entailed reading and re-reading all the transcripts carefully to get a sense of the whole, and then commencing to code the data according to themes and subthemes. Verbatim transcripts were also sent to an independent coder, a nurse educator with extensive experience in qualitative studies, to analyse the data independently in accordance with the Tesch protocols. A consensus meeting was held between the researcher and the 
independent coder for discussions on themes and subthemes, and to verify that there were similar patterns and themes.

\subsection{Trustworthiness}

The Lincoln and Guba ${ }^{[28]}$ criteria of trustworthiness, which include credibility, transferability, dependability, and confirmability, were applied to ensure the rigour of the qualitative data.

\subsubsection{Credibility}

Credibility was achieved through prolonged engagement, triangulation, and member checking. Prolonged engagement was ensured by spending sufficient time collecting data and taking field notes to enrich the collected data. The researcher was immersed in the data through repeated listening to the captured content of the tape recordings and internalising it. Triangulation was ensured by requesting the assistance of an independent co-coder to add dimension and a different perspective to the interpretation of the findings. To ensure member checking, the researcher verified findings by going back to the participants with identified categories after the data analysis and conducting follow-up interviews to verify the categories and subcategories, and whether they were correctly quoted and interpreted.

\subsubsection{Transferability}

Transferability was ensured by providing a thick comprehensive description of the method of study so that anyone interested in transferability had the basic information. The use of a purposeful sampling method increased transferability as it ensured that participants with information regarding factors that contributed to nurse educators resigning from nursing colleges was utilised in the study.

\subsubsection{Dependability}

Dependability was achieved through providing rich and detailed descriptions that showed the logic and manner in which knowledge gained from the nurse educators was developed A comprehensive description of the research method was provided. The researcher also kept field notes relating to each participant's statements, and these field notes and the audiotapes compiled during data collection were kept in a safe place. These were also forwarded to the co-coder to analyse and interpret the findings independently.

\subsubsection{Confirmability}

Confirmability was ensured by means of an audit trail of field notes and audiotape recordings of the interviews, the rationale, design, methodology and strategies used in the study. The consensus discussion between researcher and independent coder to verify the accuracy of data analysis formed part of the audit trail.

\subsection{Ethical considerations}

Permission to conduct the study was obtained from the university's Academics Ethics Committee (AEC54/02-2010) before the study could be conducted. Permission was also sought and granted by the relevant college research structure and provincial authorities. All participants voluntarily participated in the study after signing an informed consent form after a thorough explanation of the purpose, objectives and methodology of the study. Participants were also informed that they had the right to withdraw from the study at any time without any consequences.

\section{RESULTS AND DISCUSSION}

The study on the factors that contributed to nurse educators resigning from a Johannesburg nursing college contributed to the emergence of three main themes: experience of an unappreciative working environment; negative influences on the 'self' of the nurse educator; and the need for career advancement and professional growth. These findings are discussed and supported by direct quotations from participants, and conceptualisation within the existing relevant literature was done to be able to derive recommendations to retain nurse educators.

\subsection{Theme 1: Experience of an unappreciative working environment}

Nurse educators identified experience of an unappreciative working environment as one of the factors that led them to resign from the nursing college. They described this experience as "unfair". Four subthemes were described, namely: unsupportive management structures; lack of recognition/appreciation; inter-collegial factors; and resourcerelated factors in the working context.

\subsubsection{Unsupportive management structures}

Nurse educators resigned from the college because of unsupportive management structures that manifested in the form of ineffective leadership and management style, a perceived prevalence of favouritism, and a lack of mentoring at the nursing college.

The participants verbalised their shock at the leadership and management style displayed by college management, as illustrated by this participant who was frustrated by the management style of the head of department (HOD), and thus found it difficult to work in that department:

"It was really frustrating and difficult for me work under an authoritative leader who treated us like children, who treated subordinates like people who could not take any initiative. She did not want us to come up with suggestions different to hers, and if we did come up with suggestions, she would 
crush them [because] she was a controlling type of a person."

The participants were discouraged by the perception that the college management at the time did not involve nurse educators in decision-making processes, and that management's word was final: "I'll say management at that time was an authoritative type of management, because when they had decided this will be done, it was done just like that." This view was supported by another participant whose HOD was described as autocratic: "The type of leadership styles contributed to my resignation because my HOD was autocratic. I was not comfortable and free enough to bring in my own input, or my differences, because my different views were not accepted."

Finnigan ${ }^{[29]}$ asserts that when leaders do not exhibit expected leadership behaviours, educators become de-motivated, frustrated, and even angry with their institution's ineffective leadership, and they ultimately resign. Transformational leadership style has been identified as an effective leadership style that can create a non-threatening environment for nurse educators' meaningful growth and teaching experiences. ${ }^{[30]}$ Empowered with attributes such as idealised influence, inspirational leadership, intellectual stimulation, and individualised consideration, transformational leaders show respect to nurse educators. ${ }^{[31]}$ Such leaders are caring, committed, empower others with a vision, and appreciate inputs from educators. ${ }^{[30]}$

Some participants indicated that HoDs practiced favouritism, by treating nurse educators differently. One participant felt that some senior nurse educators received favourable treatment from their HOD because they were of the same ethnic group: "I found that the HOD favoured the senior people and it was evident, even during performance management reviews, because they spoke the same language, and this also frustrated me and I did not like it."

Adding to the participants' frustration was the prevalence of divisive groups at the college. One of the participants described these groups as "cliques" that made it difficult for a new nurse educator to look at issues objectively: "I felt like I wasn't going to grow in that type of environment because there were cliques and I did not know if I would fit [in] with them, and which clique to join. This was very uncomfortable for me."

Thus, stereotyping at the nursing college created discriminatory practices leading to the prevalence of cliques, and managers having favourites based on language, clan, or cultural background. ${ }^{[32]}$ Tjale and colleagues' study ${ }^{[33]}$ revealed that there was a lot of favouritism practiced in different departments at Gauteng nursing colleges, including during the

Published by Sciedu Press implementation of nurse educators' performance management reviews. Thus, nurse educators resigned because they were frustrated that they were not treated as equals by their colleagues and managers.

Linnehan and Konrad ${ }^{[34]}$ assert that intergroup inequality results in stigmatisation and prejudice leading to less powerful employees resigning because they resent unjust treatment because it is emotionally exhausting. Managers are encouraged to role-model a respect for diverse cultural backgrounds and encourage engagement in collegial conflict resolution. ${ }^{[35]}$ College management should establish a positive diversity environment in which educators of different cultural backgrounds feel their career advancement is protected from discrimination. ${ }^{[36]}$ One method that is recommended for the improvement of cohesion amongst teams, is team-building. This facilitates communication amongst staff, and can address conflict more directly, resulting in more cohesive teams and flattening of hierarchies. ${ }^{[37]}$

Participants also identified lack of mentoring as one of the factors that college management failed to provide, which led to some nurse educators resigning because they felt that they were not supported by management. One of the participants had to confront the departmental HOD in an attempt to ensure that she was mentored. She said: "I was even brave to say, 'when are you going to come and mentor me in class? When are you going to come and guide me? You are supposed to evaluate and rate my performance in class!" Another participant felt that sometimes the senior nurse educators were not as supportive or exemplary to their juniors as is the expectation of potential mentors. The participant said: "From my observations, the junior nurse educators like myself were full of energy and we wanted to get things done in time, but in that college, you realised that it was the senior, experienced nurse educators who delayed the process."

The participants' desperate plea to be allocated mentors is due to their recognition that mentoring brings about personal and professional growth. ${ }^{[35]}$ According to Blauvelt and Spath ${ }^{[38]}$ newly employed nurse educators would benefit immensely if the institution had a structured mentoring programme, with experienced educators as mentors. The authors ${ }^{[38]}$ strongly suggest that such a programme be integrated with the orientation programme. However, in the absence of mentors, nurse educators are advised to take the initiative and find resources, read extensively, conduct research and observe other educators as they teach. ${ }^{[39]}$

\subsubsection{Lack of recognition and appreciation}

Nurse educators resigned from the college because they felt unappreciated in terms of the salaries they earned. Participants indicated that their salaries did not match their qualifi- 
cations. A participant felt that even after the implementation of the OSD in July 2007, the remuneration earned by nurse educators was still similar to that of general nurses in the clinical areas:

"When it comes to remuneration for the nurse educators at the college, there was no value for money, and at lectures we were not regarded as a speciality, instead we were treated as generalists [and] we were put in the salary scale of chief professional nurses in the wards."

That statement was supported by another participant who said: "You would work hard, you study, you get highly qualified, and yet you are not recognised as such, you know salary-wise." Some participants felt disillusioned by the fact that their salaries did not correspond with their work experience as nurse educators, or with the workload they were faced with at the college: "I resigned because there was no comparable remuneration for the level of qualification and experience one had, and the level that one was performing at."

Participants resigned because they perceived college management to be unsupportive and unappreciative of their work efforts. Nurse educators are more likely to feel connected, valued and retained when they feel that they are supported in their teaching activities by their colleagues and managers. ${ }^{[40]}$ However, when they perceive a lack of meaningful recognition, nurse educators experience discontent, fatigue, burnout, and leave academia. ${ }^{[41]}$

The participants resigned out of frustration because of low salaries, which they attributed to the OSD. They were disappointed that the OSD had not yet addressed remuneration concerns of nurse educators, which were not different from those of clinical nurse practitioners. Uncompetitive salaries and benefits have been identified as one of most frequently identified reasons for nursing educator resignations. ${ }^{[42]}$ Therefore, the national Department of Health is advised to facilitate engagement with relevant stakeholders for the purpose of reviewing the OSD for nurse educators before they get frustrated and resign from nursing colleges. ${ }^{[7,43]}$

\subsubsection{Inter-collegial factors}

The participants indicated that a lack of teamwork as well as resistance to change, which were attributed to fellow nurse educators and heads of departments, frustrated the participants to the point that they resigned from the nursing college. Participants were disappointed that their fellow nurse educators did not exhibit any inclination towards teamwork during the execution of their duties, especially in activities that required involvement, co-operation, and the active participation of other nurse educators. One participant described the stressful and frustrating situation:

"At times we were supposed to work in a team, and you would find that there were colleagues who were not as committed to the work as some other team members were. Sometimes they would arrive late for scheduled meetings, or only do half of the work delegated, and this made the group fail in meeting the deadlines."

Academic staff resign from their institution when they encounter interpersonal relationships and lack of teamwork. ${ }^{[4]}$ Ambrose and colleagues ${ }^{[45]}$ warn that when there is no teamwork in the departments, divisions and factions develop, thus creating isolation, suspicion, and resentment, causing intradepartmental tensions and leaving little room for collegiality. Thus, it is recommended that the college should promote an environment that values mutual trust and respect and where there is unconditional acceptance of staff, irrespective of differences in opinions. This will always require effective conflict management and the use of participative management by the college management, so that nurse educators feel they are included in all the decision-making and problemsolving processes. ${ }^{[46]}$

Some nurse educators resigned from the nursing college because they were frustrated with resistance to change in the different spheres of their work environment. The resistance to change that was encountered by the participants mostly manifested during interactions amongst nurse educators themselves, especially on issues relating to facilitation of learning. Resistance to change was evident in senior nurse educators who were not comfortable with reviewing and updating old educational programmes. A participant shared the following: "We were once given a task to review the curriculum and when I suggested that certain aspects needed to be changed, I met a lot of resistance. The senior lecturers used to say, 'It has always been like this, why are we changing it now?",

The resistance to change has had a negative effect on the relationship between the new nurse educators and senior nurse educators. Senior nurse educators felt threatened when junior nurse educators questioned the old system of teaching and use of outdated teaching resources.

A participant also pointed out that there was resistance to change on the part of some senior nurse educators on issues pertaining to technological advances at the college. A participant said: "Any work that needed computer technical skills would be given to us, the junior nurse educators, adding more workload on those of us who were computer literate".

Participants resigned because of frustration brought about by senior nurse educators who were not receptive to new in- 
novative and creative ideas relating to facilitation of student learning. Starr ${ }^{[47]}$ concurs with the participants when asserting that academic staff feel disillusioned and resign when they experience resistance to change by colleagues in the institution. Gazza and Shellenbarger ${ }^{[48]}$ assert that experienced nurse educators may not be open to new ideas presented by new nurse educators whom they view as competition and feel threatened by them. Therefore, new nurse educators need to learn how to present alternative approaches and ideas to experienced educators in a non-threatening manner, so that their ideas can be embraced. College managers should not ignore or leave behind those resistant to change, but instead encourage collaboration amongst the differing groups.

\subsubsection{Resource-related factors in working context}

The participants felt unhappy about the lack of supportive infrastructure that was necessary for the nurse educators to create effective student learning experiences. The participants expressed their disappointment that the college had neither sufficient nor up to date supportive infrastructure. This is evidenced in the following citation:

"The computers were not working, and there was no internet in the offices. Even the library did not have such facilities, especially for students to take the initiative of searching for information on their own."

This assertion was supported by another participant who was concerned and disappointed that the college library did not have up-to-date sources of information: "There were no sources of information, and I was disappointed because I thought that the library would serve as a resource centre and would have the latest developments in any subject taught at the college."

Another participant indicated that the unavailability of equipment in the clinical area made it difficult for students to integrate theory and clinical practice:

"There was a shortage of equipment. You would go to the ward to demonstrate certain procedures to students, and you would spend three quarters of the time running around and trying to get the proper equipment. Students would ask lecturers why they were being taught certain procedures during skills week, whereas there was no equipment such as urinometers, or even screens at the clinical area to practice those procedures."

Nurse educators felt unsupported during their day to day functioning at the nursing college as there was insufficient, outdated or non-existence teaching equipment and infrastructure. Mixer et al. ${ }^{[35]}$ urge nursing education institutions to role model caring by providing a caring leadership that provides adequate resources for teaching and learning. An

Published by Sciedu Press institution can demonstrate appreciation for its educators by providing adequate staffing, financial, physical, technological resources and comfortable work conditions. ${ }^{[49]}$ Nurse educators resigned as they felt inadequate when teaching with outdated equipment that was out of synch with students' expectations of the college as a digitally savvy institution, Thus, the nursing college should invest in interactive education technologies that support students' learning needs. College management should support nurse educators by supplying them with resources that enable them to implement effective teaching strategies that enhance critical thinking among students. ${ }^{[50]}$ Similarly, the college management should invest in essential academic infrastructure, in order to ensure that they offer quality education. ${ }^{[51]}$ In the absence of these, nurse educators will resign because nurse educators become dissatisfied when they find that they can no longer do what they were educated to do in an adequate, proper, and safe way. ${ }^{[52]}$

\subsection{Theme 2: Negative influences on the 'self' of the nurse educator}

Nurse educators indicated that another factor that made them to resign from the nursing college was because of experiences that negatively influenced the 'self' of the nurse educator to an extent that they felt psychologically unsafe. The subtheme described under this theme is Poor attitudes and emotional distress.

\subsubsection{Poor attitudes and emotional distress}

Poor attitudes and emotional distress manifested through victimisation, harassment and bullying by colleagues and the college management towards fellow nurse educators and students. Nurse educators experienced an array of emotions including sadness, anger, disappointment, disillusionment, and feeling unwanted. A participant who was a clinical preceptor at the time, was almost in tears when describing the mean and cruel ways in which the students were treated by some nurse educators. The participant said: "I used to feel sorry for the students because some of the lecturers used to harass them during the evaluations and students would even end up crying, and that also contributed to my pain."

A visibly upset participant described the emotional distress wrought upon a student by an HoD during a formative clinical examination: "The HoD came in late when I had already started the evaluation, then she traumatised the student, instead of sitting and listening to the student and allowing the situation to proceed she harassed the student. I stood up, comforting a frightened student, but the HoD continued to scream at the student, ignoring me."

One participant described bullying by an HoD as making them feel "less of a person". The bullying described by the 
participants also corresponded with the management and leadership styles at the time, which were described by the participants as authoritative, autocratic, and bureaucratic.

Another participant described an HoD as a bully after observing the way she belittled staff: "I resigned because I was frustrated by the leadership style of my HoD. To me, she was a bully - a person who treated other professional people like children!"

Participants were emotionally overwhelmed when they felt verbally abused, belittled and undermined either by their colleagues, or by the college management. They could not bear witness to student victimisation and harassment as these acts were not conducive to student learning. They did not want to be coerced to conform to decisions they were not comfortable with. Clark and Ritter ${ }^{[52]}$ report that nurse educators sometimes have to deal with uncivil behaviours in the academic environment such as the use of vulgar language; demeaning remarks, unsupportive colleagues, and the exclusion and marginalisation of colleagues. The educational institution's failure to take action against the perpetrators of uncivil acts result in psychological or physiological distress in individual nurse educators, their teams and the institution itself. ${ }^{[52]}$ It is the duty of college management to create an environment that makes nurse educators and students feel safe, promotes teaching and learning, and self-worth. ${ }^{[34]}$ Clark and Ritter ${ }^{[53]}$ assert that leaders should role model civility, be observant of signs of incivility, prevent uncivil behaviours from worsening, and ensure that reports of abusive behaviour are swiftly and fairly addressed.

The experience of emotional distress suffered by nurse educators was further exacerbated by lack of wellness facilities. Thus, the nurse educators resigned because they felt that the college did not cater for their health needs. Lack of wellness policies meant that the nurse educators did not receive proper support during stressful times. A participant said:

“... there was not even an employee wellness programme for nurse educators at the college, so you didn't know where to go to [relieve your] stress. There were no debriefing exercises. There was no plan that benefited the employees of the college. Students were offered counselling services by student counsellors, but there was no such [service] for nurse educators".

The nursing college should have wellness programmes in place to prevent further complications of stress on nurse educators. At individual level, nurse educators can engage in self-care initiatives that promote their work-life balance. Examples are focused on areas of physical, psychosocial and financial well-being. ${ }^{54]}$ Nurse educators can also engage in self-care activities such as mindfulness exercises, deep breathing exercises, and taking time to do artworks such as tapestry and painting. ${ }^{[55]}$ Harmon et al. ${ }^{[56]}$ recommend meditation and yoga classes, retreat activities such as mindful breathing, walking, good nutrition, reflective journaling, and group sharing. Communicating with supportive colleagues about stressful interactions helps nurse educators to develop resilience, and instead of feeling vulnerable, they would then feel energetic, empowered, optimistic, and hopeful about their workplaces and their careers, and would thus be retained at the nursing college. ${ }^{[57,58]}$ Thus, nurse educators can also support each other by openly talking with their colleagues about the abusive practices in the nursing college, because communicating frankly with colleagues facilitates healing from traumatic experiences.

\subsection{Theme 3: Need for career advancement and profes- sional growth}

Some of the participants resigned from the nursing college because they felt there were no opportunities for them to grow in their profession and careers as nurse educators. One subtheme was described under this theme, namely, Lack of career and professional development.

\subsubsection{Lack of career and professional development}

The participants highlighted that there were limited opportunities for being promoted from nurse educator, whose primary role is to facilitate learning in class, to HoD or college principal. They also stated that the scarcity of senior positions in the nursing college made them feel as if they had reached a ceiling, as pointed out by this participant:

"For us as nurse educators, from the time you start there you become a junior lecturer, you have reached your ceiling, you will never go beyond that unless somebody who is in a senior position dies."

The promotion possibilities at a nursing college for nurse educators are HoD, vice-principal and principal, but these are dependent on the availability of vacant posts. It is therefore evident that it would take a long time for nurse educators to be promoted from one level to the next. Nurse educators resigned and endeavoured to search for better opportunities elsewhere, because they wanted to acquire a range of skills so that they could adapt to work in a variety of positions in different institutions during their working life. ${ }^{[59]}$ However, it remains an employee's primary responsibility to plan for their own career development. The supervisor's role in career development of the employee is to provide support, advice, and feedback to the employee. ${ }^{[60,61]}$

Another participant was disappointed and incredulous after being denied study leave, such that she felt that the only 
option left to her was to resign in order to continue with her studies: "I told myself that maybe I should just resign so that I could focus on continuing and finishing my studies, the workload was too much, and I was not able to study part-time."

Career development is an ongoing, formalised effort taken by an organisation to ensure that employees with the proper qualifications and experiences are available when needed. ${ }^{[60,61]}$ Thus, to develop their careers, individuals need to improve their skills, education and experiences, as well as modify their behaviours, so that they can work better and add value in their workplace. The employer is also expected to communicate the availability of senior posts to all nurse educa- tors. Nurse educators are advised to practice the following activities outlined in Billings and Kowalski ${ }^{[62]}$ in order to plan and develop their careers: environmental scanning; selfassessment; creation of a career vision; development of a strategic career plan; and marketing.

Other participants resigned because no in-service training was offered to them that were relevant to the specific courses that they facilitated. They were also concerned that they were not attending conferences relevant to their teaching specialities that could be used to inform nursing education and practice at the college. A participant said: “... there was no in-service training provided by the college to address my area of specialty."

Table 1. Recommendation to retain nurse educators

\begin{tabular}{|c|c|}
\hline Theme & Recommendations \\
\hline $\begin{array}{l}\text { Unappreciative working } \\
\text { environment }\end{array}$ & $\begin{array}{l}\text { Retain nurse educators through utilisation of effective leadership styles to create a caring and } \\
\text { appreciative environment: } \\
\text { - Provide sufficient teaching and learning infrastructure and equipment to optimise nurse } \\
\text { educator's performance } \\
\text { - Invest in technology-driven teaching and learning } \\
\text { - Facilitate review of nurse educator salary structures } \\
\text { - Adopt a transformational leadership style } \\
\text { - Utilise participative style of management to promote dynamic interactive decision-making } \\
\text { and problem-solving } \\
\text { - Develop a mentoring programme } \\
\text { - Create a caring environment that facilitates cohesiveness among nurse educators. } \\
\text { - Encourage formation of reflective practice groups and communities of practice }\end{array}$ \\
\hline $\begin{array}{l}\text { Negative influences on the } \\
\text { "self" }\end{array}$ & $\begin{array}{l}\text { Retain nurse educators by eradicating uncivil behaviours: } \\
\text { - Establish an Employee Wellness Unit for the provision of physical and mental health services } \\
\text { - Develop and implement policies for reporting and addressing incivility in the institution } \\
\text { - Maintain a zero-tolerance approach towards victimisation, bullying, and harassment } \\
\text { - Offer training that empowers nurse educators in dealing with emotional abuse } \\
\text { - Champion initiatives aimed at nurse educator self-care and resilience }\end{array}$ \\
\hline $\begin{array}{l}\text { Career advancement and } \\
\text { professional growth }\end{array}$ & $\begin{array}{l}\text { Retain nurse educators through creation of an environment that is conducive to career development } \\
\text { activities: } \\
\text { - Nurse educators should lead own career-planning within the nursing college } \\
\text { - Facilitate a learning culture by offering developmental programmes for educators, for } \\
\text { example in-service training } \\
\text { - Offer career counselling to nurse educators during performance appraisal reviews } \\
\text { - Encourage use of networking as a tool to facilitate the development of professional identities } \\
\text { with peers }\end{array}$ \\
\hline
\end{tabular}

Nurse educators become frustrated and leave teaching when they feel they are not developing in their profession. ${ }^{[63]}$ Nurse educators prefer to work in environments where their managers provide them with information, support, resources, and opportunities to improve their own status within the institution. Individual nurse educators have a responsibility of identifying their own learning needs, based on their in- terpretation of the current and future trends in their living and working environment. This internally driven capability is known as self-directed learning, which is a person's acceptance of his or her responsibility for his or her learning, and a readiness to engage in developmental processes. ${ }^{[64]}$ Nurse educators therefore need to attend workshops and local and international conferences and pursue further training related 
to their area of interest and the subjects they teach, to update their skills that bring meaningful improvement to student performance.

The role of the institution is to aid its educators through supportive policies and a learning culture, so that educators can commit themselves to personal and professional development, which results in better individual performance and higher individual satisfaction. ${ }^{[65]}$ Nurse educators should be advised to continually develop their knowledge and stimulate their thinking towards personal fulfilment as they attain practical skills and knowledge to apply in real-world environments. For a learning culture to ensue in the institution, college managers should deliberately provide nurse educators with suitable learning environments that nurture sustained learning. ${ }^{[66]}$ Nurse educators should be supported to attend workshops, local and international conferences, and pursue further training related to their area of interest and the subjects they teach. College managers should also lead by example when it comes to continuing professional development, as nurse educators also look up to their leaders for role modelling and guidance.

\subsection{Recommendations}

This study revealed a variety of factors that contributed to the resignation of nurse educators at the nursing college in Johannesburg. These were classified as an unappreciative working environment, negative influences on the 'self', and the need for career advancement and professional growth.

In Table 1, the recommendations to retain nurse educators were derived from the discussions above and conceptualisation within the existing relevant literature.

\subsection{Limitations of the study}

The study provided rich discussions on the factors that contributed to the resignation of nurse educators at a public nursing college in Johannesburg and how they could be retained. However, the findings lack generalisability to other nursing colleges due the contextual nature of the study and the unique experiences. There is an opportunity for interested researchers to replicate to other colleges. The study only explored and described the perceptions of nurse educators. Thus, it is recommended that future studies should seek to understand the perceptions of college management on the phenomenon, as well as evaluate the exit interviews of nurse educators who resigned.

\section{Conclusion}

The factors that contributed to the resignation of nurse educators at the nursing college in Johannesburg were found to be predominantly linked to the nurse educators' experiences of an unappreciative working environment. This environment negatively influenced the 'self' of the nurse educators, making them feel psychologically unsafe. Experiences of ineffective management practices emerged as the most common reason for resignation in this context. Additionally, personal-oriented factors emerged as a need for career advancement and professional growth. Recommendations were described to create an appreciative working context as well as to address the nurse educators' need for career advancement and professional development.

\section{CONFlicts of InTEREST Disclosure}

The author declares that there is no conflict of interest.

\section{REFERENCES}

[1] South African Department of Health. Strategic Plan for Nursing Education, Training and Practice 2012/13-2016/17. Pretoria: Government Printers. 2013.

[2] Cash PA, Doyle RM, von Tettenborn L, et al. Working with nurse educators' collective wisdom: Implications for recruitment and retention. Nursing Economic. 2011; 29(5): 257-264.

[3] Bvumbwe T, Mtshali N. Nursing education challenges and solutions in Sub Saharan Africa: An integrative review. BMC Nursing. 2018; 17(3). https : //doi.org/10.1186/s12912-018-0272-4

[4] Harries J. Challenges of nursing faculty retention. The Midwest Quarterly. 2019; 60(3): 251-269.

[5] South African Department of Health. Nursing Strategy for South Africa. Pretoria: Government Printers. 2008.

[6] South African Department of Health. National strategic direction for nursing and midwifery education and practice: A road map for strengthening nursing and midwifery in South Africa 2020/212025/26. Pretoria: Government Printers. 2020.
[7] Democratic Nursing Organisation of South Africa. DENOSA urges SA government to develop staff retention before nurses are lost to the UK again! 2019. Available from: https://www.denosa.org .za/Media_View.php?id=36074

[8] Willis-Shattuck M, Bidwell P, Thomas S, et al. Motivation and retention of health workers in developing countries: a systematic review. BMC Health Service Research. 2008; 8: 247. https : //doi.org/10.1186/1472-6963-8-247

[9] Heneman III HG, Judge TA. Staffing Organizations. 6th ed. Mendota House, Middleton: McGraw-Hill. 2009.

[10] Leners DW, Wilson VW, Connor P, et al. Mentorship: Increasing retention probabilities. Journal of Nursing Management. 2006; 14(8): 652-654. https://doi.org/10.1111/j.1365-2934. 20 $06.00641 . \mathrm{x}$

[11] Uthaman T, Chua TL, Ang SY. Older nurses: A literature review on challenges, factors in earl retirement and workforce retention. Proceedings of Singapore Healthcare. 2016; 25(1): 50-55. https : //doi .org/10.1177/2010105815610138 
[12] Brady MS. Recruitment and retention of associate nursing faculty. Journal of Nursing Education. 2007; 46(4): 190-192.

[13] Coetzee CM. A workload model for nurse educators in private higher education: options for improved productivity and job satisfaction. $\mathrm{PhD}$ thesis, University of Stellenbosch. 2019.

[14] Jacobson DA. Causes and effects of teacher burnout. Doctoral dissertation, Walden University, Minneapolis. 2016.

[15] Falk NL. Strategies to enhance retention and effective utilization of aging nurse faculty. Journal of Nursing Education. 2007; 46(4): 165-169.

[16] Sodidi KA, Jardien-Baboo S. Experiences and mentoring needs of novice nurse educators at a public nursing college in the Eastern Cape. Health SA Gesondheid. 2020; 25(0): 1-8. https://doi.or $\mathrm{g} / 10.4102 / \mathrm{hsag} \cdot \mathrm{v} 25 \mathrm{i0} .1295$

[17] Xaba J, Phillips G. Understanding nurse emigration: Final report. Trade Union Research Project commissioned by DENOSA. 2001. Available from: http://www.queensu.ca/samp/migrationres ources/braindrain/documents/xaba.pdf

[18] World Health Organisation. 2020. State of the world's nursing 2020: investing in education, jobs and leadership. Geneva: World Health Organization. Available from: https://www . who.int/publicat ions/i/item/9789240003279

[19] City of Johannesburg. (2021). About the city: Economy and infrastructure. Available from: https://www . joburg.org.za/ab out_/Pages/About $\% 20$ the $\% 20$ City/About $\% 20$ the $\% 20$ City $\% 2$ 02/Economy-and-infrastructure.aspx

[20] Ndawo MG. Factors influencing nurse educators' teaching and learning performance at a nursing college in Gauteng. MCur dissertation, University of Johannesburg, Auckland Park. 2014.

[21] Gauteng Department of Health. Annual Performance Plan 2009/10-2011/12. 2009. Available from: http://www.health.g pg.gov.za/GDoHAPP2009-10.pdf

[22] Gauteng Department of Health. Annual Performance Plan 2016/172018/19. 2016. Available from: https://www.fast-trackciti es.org/sites/default/files/Gauteng\%20Province $\% 20 \mathrm{Pe}$ rformance $\% 20 \mathrm{Plan} \% 20 \% 282016 \% 29$.pdf

[23] South African Nursing Council. Education and training guidelines for Advanced Diploma in Midwifery (NQF Level 7). Available from: https://www.sanc.co.za/wp-content/uploads/2020/08 /Education-and-Training-Guidelines-for-Adv-Dip-pro g-Midwifery.pdf

[24] South African Nursing Council. Education and training guidelines for Postgraduate Diploma programme. 2020. Available from: https://www.sanc.co.za/wp-content/uploads/2020/08 /Education-and-Training-Guidelines-for-Postgraduat e-Diploma-Programmes.pdf

[25] African National Congress. A National Health Plan for South Africa. Maseru: Bahr Mapping and Printing. 1994.

[26] Silverman D. Interpreting qualitative data. Methods for analysing talk, text and interaction. 3rd ed. Thousand Oaks: SAGE Publications; 2006.

[27] Creswell JW. Research design. Qualitative, quantitative, and mixed method approaches. 3rd ed. Los Angeles: SAGE Publications. 2009.

[28] Lincoln YS, Guba EG. Naturalistic Inquiry. California: SAGE Publications. 1985

[29] Finnigan KS. Principal leadership in low-performing schools: A closer look through the eyes of teachers. Education and Urban Society. 2012; 44(2): 183-202. https://doi.org/10.1177/001312 4511431570

[30] Worthy K, Dawson RM, Tavakoli AS. Relationships among nursing deans' leadership styles and faculty job satisfaction levels. Journal of
Nursing Education. 2020; 59(2): 68-75. https : //doi .org/10.3 928/01484834-20200122-03

[31] Marquis BL, Huston CJ. Leadership roles and management functions in nursing. Theory and application. 7th ed. Philadelphia: Wolters Kluwer Health. 2012.

[32] Rangarajan N, Black T. Exploring organizational barriers to diversity: A case study of the New York State Education Department. Review of Public Personnel Administration. 2007; 27(3): 249-263. https://doi.org/10.1177/0734371X06296203

[33] Tjale MP, Bhana VM, Mulaudzi FM. The utilisation of performance management and development systems for continuous professional development of nurse educators. Journal of Contemporary Management. 2019; 16: 450-471. https://doi.org/10.35683/jcm18 043.0022

[34] Linnehan F, Konrad AM. Diluting diversity: Implications for intergroup inequality in organizations. Journal of Management Inquiry. 1999; 399-414.

[35] Mixer SJ, McFarland MR, Andrews MM, et al. Exploring faculty health and wellbeing: creating a caring scholarly community. Nurse Education Today. 2013; 33(12): 1471-1476. https: //doi.org/10.1016/j.nedt.2013.05.019

[36] Kaplan DM, Wiley JW, Maertz CP. The role of calculative attachment in the relationship between diversity climate and retention. Human Resource Management. 2011; 50(2): 271-287. https : //doi.org/10.1002/hrm. 20413

[37] Stoller JK. Building teams in healthcare. Chest Publications. 2020 https://doi.org/10.1016/j. chest.2020.09.092

[38] Blauvelt MJ, Spath ML. Passing the torch: A mentoring program at one school of nursing. Nursing Education Perspectives. 2008; 29(1): 29-33. https://doi.org/10.1016/j.gerinurse .2007 .11 .010

[39] Carr ML, Pastor DK, Levesque PJ. Learning to lead: Higher education faculty explores self-mentoring. International Journal of Evidence-Based Coaching and Mentoring. 2015; 13(2): 1-13.

[40] Ebert L, Mollart L, Nolan SJ, et al. Nurses and midwives teaching in the academic environment: An appreciative inquiry. Nurse Education Today. 2020; 84. https://doi.org/10.1016/j.nedt.2019.10 4263

[41] American Association of Critical Care Nurses. AACN standards for establishing and sustaining healthy work environments: A journey to excellence. 2nd ed. 2016. Available from: https://www . aacn .org/ /media/aacnwebsite/nursing-excellence/health $\mathrm{y}$-work-environment/execsum.pdf?la=enPublished2016

[42] Kuehn MB. Creating a healthy work environment for a nurse faculty. Creative Nursing. 2020; 16(4): 193-197. https ://doi .org/10.1 891/1078-4535.16.4.193

[43] Netshiswinzhe MD, Mulaudzi FM. Perceptions of nurse educators regarding the implementation of the occupational specific dispensation at a selected nursing college in Limpopo Province. Health SA Gesondheid. 2015; 20(1). https://doi.org/10.1016/j.hs ag. 2015.04.003

[44] Gwavuya F. Leadership influences on turnover intentions of academic staff in tertiary institutions in Zimbabwe. Academic Leadership: The Online Journal. 2011; 9(1). Available from: http://www.academicleadership.org/article/leaders hip-influences-on-turnover-intentions-of-academi c-staff-in-tertiary-institutions-in-zimbabwe

[45] Ambrose S, Huston T, Norman M. A qualitative method for assessing faculty satisfaction. Research in Higher Education. 2005; 46(7): 803-830. https : //doi .org/10.1007/s11162-004-6226-6

[46] Muller M. Nursing dynamics. 4th ed. Johannesburg: Heinemann. 2009.

Published by Sciedu Press 
[47] Starr K. Principals and the politics of resistance to change. Educational Management Administration \& Leadership. 2011; 39(6): 646-660. https ://doi .org/10.1177/1741143211416390

[48] Gazza EA, Shellenbarger T. Successful enculturation: Strategies for retaining newly hired nursing faculty. Nurse Educator. 2005 30(6): 251-254. https://doi.org/10.1097/00006223-20051 1000-00009

[49] Brady M. Healthy nursing academic work environments. Online Journal of Issues in Nursing. 2010; 15(1). https : //doi .org/10.391 2/0JIN. Vol15No01Man06

[50] Simpson E, Courtney M. Implementation and evaluation of critical thinking strategies to enhance critical thinking skills in Middle Eastern nurses. International Journal of Nursing Practice. 2008 14: 449-454. https://doi.org/10.1111/j.1440-172X.2008 $.00719 . \mathrm{x}$

[51] South African Department of Higher Education and Training. Green paper for post-school education and training. Pretoria. 2012. Available from: http://www.dhet.gov.za/portals/0/Documents/ .../Green\%20Paper.pdf

[52] West E. Back to the basics: Recruitment, retention, and reality. MEDSURG Nursing. 2004; 13(5): 346-350.

[53] Clark CM, Ritter MS. Policy to foster civility and support a healthy academic work environment. Journal of Nursing Education. 2018; 57(6): 325-331. https://doi.org/10.3928/01484834-20180 522-02

[54] Farber JE, Payton C, Dorney P. Life balance and professional quality of life among baccalaureate nurse faculty. Journal of Professional Nursing. 2010; 36: 587-594. https://doi.org/10.1016/j.pr ofnurs. 2020.08.010

[55] Wong YLR. Knowing through discomfort: A mindfulness-based critical social work pedagogy. Critical Social Work. 2004; 4(1).

[56] Harmon RB, DeGennaro G, Norling M, et al. Implementing healthy work environment standards in an academic workplace: An update.
Journal of Professional Nursing. 2018; 34(1): 20-24. https//doi .org/10.1016/j.profnurs.2017.06.001

[57] Glass N. An investigation of nurses' and midwives' academic/clinical workplaces: A healing model to improve and sustain hope, optimism and resilience in professional practice. Holistic Nursing Practice. 2009; 23(3): 158-170. https://doi.org/10.1097/HNP. Ob013e $3181 \mathrm{a} 056 \mathrm{c} 4$

[58] Heinrich KT. An optimist's guide for cultivating civility among academic nurses. Journal of Professional Nursing. 2010; 26(6): 325-331. https://doi.org/10.1016/j.profnurs .2010.07.002

[59] Muller M, Bezuidenhout M, Jooste K. Healthcare service management. 2nd ed. Cape Town: Juta \& Co. 2011.

[60] Byars LL, Rue LW. Human resource management. 9th ed. New York: McGraw-Hill Irwin. 2008.

[61] Mondy RW, Noe RM. Human resource management. 9th ed. New Jersey, Pearson Prentice Hall. 2005.

[62] Billings DM, Kowalski K. Developing a career as a nurse educator. Journal of Continuing Education in Nursing. 2008; 39(8): 343-344. https://doi.org/10.3928/00220124-20080801-02

[63] Bruce J, Klopper HC, Mellish JM. Teaching and learning the practice of nursing. 5th ed. Cape Town, Heinemann Publishers. 2011.

[64] Van Rensburg GH, Botma Y. Bridging the gap between self-directed learning of nurse educators and effective student support. Curationis. 2015; 38(2): 1-7.

[65] Bui H, Baruch Y. Creating learning organizations in higher education: A systems perspective. https://doi.org/10.1108/0969 6471011034919 The Learning Organisation. 2010; 17(3): 208-227. https://doi.org/10.1108/0969647101103491

[66] Kools M, Stoll L, George B, et al. The school as a learning organisation: The concept and its measurement. European Journal of Education. 2020; 55(1): 24-42. https ://doi.org/10.1111/ej ed. 12383 